\title{
Os Partidos Políticos em Weber
}

\author{
José Carlos M. Belieiro Júnior ${ }^{1}$
}

A

obra de Weber foi explorada em seus múltiplos aspectos e temas por uma infinidade de comentaristas e especialistas de todas as nacionalidades. No entanto, um dos temas pouco explorados de sua imensa produção intelectual são os partidos políticos. Embora seja raro qualificar Weber como um teórico dos partidos, isso não quer dizer que a análise do fenômeno partidário não tenha recebido um tratamento mais sistemático por parte de Weber em suas obras políticas. Assim, tanto em dois textos importantes, como em A Política Como Vocação como em Parlamento $e$ Governo na Alemanha Reordenada, e o capítulo do segundo volume de Economia e Sociedade, Weber vai se voltar a esse relevante objeto da ciência política, dessas que são uma das maiores organizações políticas do mundo moderno. ${ }^{2} 0$ que pretendo desenvolver neste artigo é uma breve análise de como Weber interpretou a questão dos partidos políticos e de que modo sua análise do fenômeno partidário é relevante, atual e esclarecedora, o que revela um Weber cientista político, por assim dizer.

Em seu texto clássico "A Política como Vocação", produto de uma conferência a estudantes universitários alemães em 1918, Weber traça um amplo panorama crítico da atividade política no mundo moderno, na qual se inclui uma exposição sobre 0 nascimento e evolução dos partidos. Como em todos os outros fenômenos que analisa, também neste caso, o autor vai buscar na comparação histórica, os ancestrais dos partidos modernos. Os exemplos que Weber dá são os agrupamentos políticos medievais, como os guelfos e os gibelinos das cidades italianas. Esses agrupamentos eram baseados fundamentalmente em séquitos pessoais, que competiam por poder político, e terras, fazendo da violência o instrumento normal da conquista. Desenvolvendo já sua crítica ao processo revolucionário que se dava na Rússia, Weber também vai buscar como exemplo de organização política pré-partidária a organização paramilitar rígida dos soviets russo.

\footnotetext{
Mestre em Ciência Política pela UsP.

2 EmA Política, a análise dos partidos está entre as páginas 84 a 104, em Parlamento e Governo, especialmente o capítulo II. Neste texto, utilizo mais $A$ Política como Vocação por entender que neste trabalho, o autor vai fazer uma análise mais sistemática do fenômeno partidário. A maioria das citações de Weber no texto são extraídas de A Política.
} 
Feitaessa consideração, podemos partirpara a definição que Weber dá aos partidos. São organizações que disputam um mercado eleitoral livremente, "sem jamais recorrer a outros meios que não os pacíficos e racionais" na busca de votos pelo poder. Outra característica importante do caráter moderno dos partidos é o livre recrutamento de seus membros. Neste ponto, Weber reforça que dada a dimensão do livre recrutamento, o controle e regulamentação estatal da atividade partidária ficaria prejudicada. Quer dizer, em outras palavras, os partidos são organizações da sociedade civil, ou da sociedade política não estatal, em que caberia uma regulamentação mínima do Estado. Weber também se opõe às propostas de representação profissional na política, que poderia transformar os partidos em feudos de grupos de interesse. Além do mais, em Economia e Sociedade, Weber vai diferenciar os partidos em dois tipos. Os que caçam empregose os partidos ideológicos. Na prática os partidos são as duas coisas juntas, mas Weber faz questão de afirmar que os exemplos de partidos "representantes de ideologias", são o Partido do Centro e a social-democracia alemã, e no caso dos caçadores de cargos, os partidos burgueses nos EUA.

A acepção moderna de partido aparece pela primeira vez na Inglaterra, mas mesmo assim, como "simples conjuntos dependentes da aristocracia". A Inglaterra é o país em que o nascimento e evolução dos partidos se deu de maneira clara, onde Weber naturalmente dedica considerável atenção em A Política. Assim, a primeira manifestação de organização partidária aparece como um partido estritamente vinculado à nobreza. Tal situação só se altera em parte devido à Reform Bill ${ }^{3}$ de 1831, mas Weber pondera que mesmo os partidos de notáveis que aparecem junto com a ascensão política da burguesia, ainda eram muito parecidos com a "estrutura dos partidos da nobreza".

0 que Weber reforça em sua análise dos partidos na Inglaterra na primeira metade do século XIXéo seu caráter eminente de organizações que funcionavam esporadicamente, e lideradas por um político não profissional. Eram clubes e associações políticas, formadas pela alta classe média, professores, advogados, membros do clero, enfim, "toda camada social que julgava pertencer à classe dos gentlemen". 0 que é pior: nem todas as cidades possuíam esse clubes, daí que neste caso, a vida política funcionava em bases bastante irregulares, carente de uma organização mínima. Só nas grandes cidades havia seções partidárias permanentes, "com mensalidades módicas pagas pelos membros, com encontros periódicos e reuniões públicas durante as quais o deputado prestava contas de seu mandato". Quer dizer "não existiam ainda partidos interlocalmente organizados como associações permanentes".

3 Weber se refere às medidas propostas pelo gabinete do whig Earl Grey, destinadas a mudar a estrutura de representação no Parlamento e a ampliação do número de cidadãos com direito a voto na Inglaterra. 
Nessa situação descrita por Weber de vida partidária ainda incipiente, cabia aos dois únicos agentes políticos as iniciativas em matéria de organização partidária e que por isso, podiam dispor de um controle total do partido: o parlamentar, e os homens de prol. 0 primeiro é um político profissional por excelência, que vive a caça de votos, e em geral, tinha assento no Parlamento, e o segundo, eram políticos que não faziam da política sua atividade principal e estavam, freqüentemente, fora do parlamento e que participavam da atividade política, seja por tradição familiar, por motivos ideológicos, motivos econômicos, mas nunca fazendo da política sua razão de vida. Eram políticos que viviam "para" a política. Importa dizer que, nessa situação, o político parlamentar tinha um papel preponderante, detendo o "monopólio dos empregos e de modo geral, todos os negócios" de sua área de influência eleitoral.

Logo se fez necessária alguma mudança organizacional nos partidos, o que Weber chamou de uma "coesão mais firme no interior dos partidos". Ditada pelo interesse do político profissional parlamentar em ampliar sua rede de alianças eleitorais em diferentes regiões e a necessidade de maior divulgação do programa do partido à camadas sociais mais amplas, acabou promovendo uma expansão da organização partidária em cidades médias do interior inglês. Mas, ainda não se conhecia a figura do funcionário partidário remunerado e do ponto de vista da estrutura organizacional, ainda se assemelhavam aos antigos partidos de "homens de projeção". Quer dizer, eram partidos de pouca ou nenhuma inserção social significativa e de funcionamento marcadamente voltado à satisfação dos interesses dos poucos participantes da atividade política, os políticos com vínculo no parlamento e as lideranças dos homens de prol. Fora isso não sobrava nada, além do que, o número de participantes na política era extremamente reduzido, certamente porque 0 direito de voto era ainda restrito.

Até agora discutimos o primeiro estágio da organização partidária, momento em que os partidos estavam sob domínio dos parlamentares edos homens de prol. De outro lado, esse primeiro estágio também é o da pequena participação política do conjunto da sociedade e finalmente, de rudimentos de organização partidária em escal a propriamente nacional.

0 segundo estágio da evolução dos partidos é radicalmente distinto do anterior. Na verdade representa um "novo estado de coisas" marcado por fenômenos estruturais que afetariam profundamente o modo de fazer política nas sociedades modernas. Esse segundo momento, como afirma Weber é "filho da democracia, do sufrágio universal, da necessidade de organizar e recrutar as massas, da evolução dos partidos no sentido de uma unificação cada vez mais rígida no topo e no sentido de uma disciplina cada vez mais severa nos diversos escalões". Aqui reside uma importante questão: o que o grande sociólogo 
quer mostrar é o nascimento dos partidos de massa, forjados no processo de alargamento da participação com a introdução do sufrágio universal, que levou os partidos a se reorganizarem num esquema de novo tipo para atender às necessidades de competição num mercado eleitoral ampliado e complexo em termos de demandas e reivindicações. ou seja, há um declínio dos partidos da nobreza, típicos da época anterior, que dão lugar a um novo tipo de partido político. É também a decadência da política dos parlamentares e dos homens de prol, que dá lugar à figura do funcionário dos partidos, liderados por um empreendedor do tipo capitalista que assume o controle da atividade política. Os exemplos sugeridos por Weber éo election agent que aparece na Inglaterra e o boss norte-americano.

Além disso, há uma outra mudança significativa que tem a ver com a dinâmica interna dos novos partidos. Entra em cena a figura do militante do partido, que passa a ter um papel relevantenaelaboração do programa partidárioe na escolhados candidatos. As assembléias partidárias seguem um rito hierárquico que dão significado ao agigantamento da participação política das massas. A consequência disso é observada por Weber como um elemento novo e decisivo para os partidos: o nascimento das máquinas partidárias e o modo como vão impor sua vontadeno interior dos partidos. Essas máquinas "podem fazer frente aos parlamentares" e "só aquele que a máquina se disponha a orientar, mesmo em detrimento da orientação partidária, poderáse transformar em chefe".

Se é assim como Weber coloca as coisas, a vontade da máquina, o interesse imediato da burocracia partidária passa a valer na escolha do melhor candidato, ou seja, o melhor candidato que atenda aos interesses objetivos da máquina, que são "posições ou vantagens outras". Naturalmente que nesse contexto é o líder demagógico de massas o que mais atende a esse interesse, ou seja, que no "decurso da campanha eleitoral, a influência demagógica da personalidade do chefe lhe assegure votos e mandatos, garanta a abertura das portas do poder, de sorte que os militantes contarão com as maiores possibilidades de obter a esperada recompensa pela devoção que demonstraram".

Essa nova forma de organização burocrática dos partidos irá evidentemente se impor em todos os países como um processo inexorável, como uma tendência à burocratização universal que atinge todas as esferas da sociedade. Mas os primeiros exemplos se manifestam, segundo Weber, no seio dos partidos burgueses nos Estados Unidos, eno famoso Partido SocialDemocrata Alemão, então o maior partido marxista naquelaépoca.

Mas não é um processo linear e isento de conflitos em que essa lógica se impõe. As antigas lideranças resistem ao domínio gradual dos funcionários e pode ocorrer "regressões", quando os interesses desse grupo não se realizam nas mãos de um chefe demagógico e será necessário fazer concessões a liderança de um político de pouca inclinação carismática. 
Além do mais, pode aparecer um político do tipo outsider, que não compactua com a máquina instalada, obrigando, neste caso, a máquina a ceder. Em todo caso, esse é um processo que não se faz sem conflitos.

Seguindo a trilha de Weber em $A$ Politica, resta agora analisar como se deu essa mudança estrutural no funcionamento dos partidos. Os dois exemplos significativos escolhidos pelo autor são mais uma vez o da Inglaterra da segunda metade do século XIX e dos Estados Unidos dos anos 1820 aos anos 1840. Na Inglaterra as coisas se passaram mais ou menos da seguinte maneira: enquanto partidos de "homens de importância", a carência de organização partidária eram enormes. De outro lado, as clivagens políticas naquele país estavam ainda sedimentados em torno de duas agremiações tradicionais, os tories e os whigs. Assentados em bases sociais diferentes, o primeiro no clero anglicano e nos grandes proprietários de terras, e o segundo nas camadas médias das cidades, o ferreiro, 0 alfaiate, 0 artesão. Os whigs tinham uma inclinação mais progressista enquanto os tories eram conservadores. Weber minimiza as ideologias propriamente políticas nessa clivagens, que para ele, são clivagens fundamentalmente de ordem econômica, religiosa ou mesmo a influência das tradições familiares. Na análise de Weber, as instituições políticas estavam separadas da sociedade. Elas "planavam", segundo ele. Muito provavelmente porquê Weber via uma carência de participação mais ampla, dando uma margem aos políticos para fazerem o que quiserem. A figura política predominante no interior dos partidos era o whip, que era um assessor do líder, fazendo a mediação entre 0 líder político e a comunidade, fazendo de fato o trabalho de patronagem e de clientela, se quisermos usar uma expressão mais próxima. A posição do whip era importante porque tinha em suas mãos a mais determinante das atribuições, o monopólio dos empregos, e a "ele deveriam dirigir-se todos os que pretendiam uma posição política e era ele quem as distribuía, após haver feito consulta aos deputados das diferentes circunscrições eleitorais".

0 fato novo e decisivo é a entrada em vigor de uma nova legislação eleitoral que perseguia como objetivos básicos, a garantia da regularidade das eleições e o controle dos gastos de campanha, a fim de evitar eventuais abusos do "poder do dinheiro" usado pelos candidatos e seus partidos nas disputas eleitorais inglesas. A consequência disso é o aparecimento de um ator político fundamental, o election agent, um empreendedor capitalista indispensável aos partidos. À primeira vista, sua função era dar uma operacionalidade aos custos eleitorais dos partidos. De outro lado, também é plausível pensar que de sua ação, seria possível instrumentalizar a legislação a favor do candidato, driblando eventuais problemas jurídicos. Mesmo diante do impacto da legislação eleitoral sobre a vida partidária, os partidos, ressalta Weber, se apresentavam em termos de "antiga 
organização" e com razoável influência dos homens de prol e dos parlamentares sobre o destino da organização. A contradição nesse caso é que, mesmo diante de um estágio evolutivo superior, pelo menos do ponto de vista organizacional, configura-se ainda a situação descrita como o primeiro estágio dos partidos políticos.

0 marco da mudança nos partidos, no sentido de uma burocratização definitiva, é o ano de 1868, quando pela primeira vez, durante as eleições gerais numa pequena cidade do interior inglês, Birmigham, apareceu o chamado sistema de caucus. Estimulado inicialmente por um pastor protestante, e motivado pelo interesse geral de democratização do voto, "acreditou-se conveniente movimentar enorme conjunto de grupos de aparência democrática, organizar em cada bairro da cidade um comitêeleitoral, manter continuidade de ação e burocratizar rigorosamente o conjunto". Qual o resultado do novo espírito? A resposta, Weber diz: "0 crescimento do número de empregados remunerados pelas comissões locais que, dentro em pouco, agruparam e organizaram cerca de dez por cento dos eleitores". Essa "nova máquina" inevitavelmente entrava em conflito com as lideranças jác consolidadas, como os parlamentares e mesmo com o whip. É difícil dizer se Weber simplifica esse processo de tomada gradual de poder levado a cabo pelos funcionários e a crescente submissão das antigas lideranças a esse grupo, basicamente movido por interesses materiais. 0 que significa dizer que, numa situação de poder consolidado dos funcionários, só é candidato o líder que agradar as massas em termos demagógicos, que é justamente o líder que irá abrir as portas do poder aos dirigentes partidários. 0 certo é que Weber estava consciente que essa era a tendência, haja vista que o primeiro teste do sistema caucus foi em 1876 durante as eleições gerais inglesas, e o resultado foi "impressionante": o Partido Liberal liderado por Gladstone saiu-se vitorioso derrotando o partido conservador do Primeiro-Ministro Disraeli. Weber atribui o sucesso eleitoral de Gladstone à suas qualidades carismáticas e sua estreita vinculação com a máquina de seu partido.

Interessante observar que esse novo estado de coisas é produto direto da ampla democratização política da sociedade inglesa dos fins do século XIX, que obriga os partidos a se adequarem a uma realidade objetivamente nova: a ampliação do mercado eleitoral. Com a Reform Act, de 1867, amplia-se significativamente o número de votantes, o que teria impacto decisivo nas eleições seguintes sob a lógica do caucus. Outro impulso decisivo do processo de burocratização é a própria dinâmica da política local, que aliás acabou demonstrando ser mais importante que a experiência política das grandes cidades inglesas. Por razões nã̃o muito bem explicitadas por Weber, o campo da política municipal parece exercer um atrativo maior à participação. A resposta de Weber certamente seria, em 
primeiro lugar, o interesse pelos cargos das administrações locais mas também há que se levar em conta as motivações ideológicas e de valor, como a preocupação genérica com a qualidade de vida na cidade, etc.

Outra dimensão relevante da dominação da burocracia partidária considerada por Weber emA Política éo tipo de controle que a máquina estabelece com o parlamentar. Como um novo sistema de dominação, os parlamentares ingleses "viram-se reduzidos à condição de bestas de votar, perfeitamente disciplinados". 0 caso alemão também é evocado por Weber para sustentar sua análise. Neste ponto, Weber quer demonstrar a perda de autonomia do parlamentar frente à máquina partidária, que exige disciplina absoluta dos seus representantes no parlamento. À frente da máquina está o chefe do partido que transforma os parlamentares em "simples detentores de prebenda". Se o chefe partidário se torna o líder máximo, um verdadeiro "ditador plebiscitário", como se dá a escolha desses chefes? Entre todas as qualidades normais exigidas, a de primeira importância é "a força da palavra demagógica", ou em outros termos, a força da qualidade carismática do líder que consiga se comunicar com as massas utilizando frequientemente meios emocionais para chegar e se manter no poder. Nada de novo, se levarmos em conta queé natural dos líderes carismáticos usar de "técnicas" de manipulação das massas pela via "puramente emocional", o que Weber naturalmente condena.

Por fim, ainda se referindo à experiência da política inglesa, há pelo menos um fato positivo destacado por Weber: o papel desempenhando pelas comissões parlamentares existentes no interior do parlamento britânico, que coloca o político numa arena qualitativamente superior, fazendo dessa atividade uma verdadeira "escola" para os políticos, obrigando-os a atuarem na verdadeira prática política como relator de comissões especiais e debatendo temas de interesse público. Essas comissões cumpririam também um papel seletivo, "com eliminação do indivíduo que não passe de um demagogo qualquer". Weber com certeza ficaria satisfeito com a experiência política brasileira dos últimos anos, em razão do papel desempenhado pelas comissões temáticas do Congresso Nacional, e mesmo as Comissões Parlamentares de Inquérito, que sem dívida contribuem para o fortalecimento da instituição.

Passemos agora à análise do caso norte-americano que, comparado com a Inglaterra, aparece como "forma atenuada de maquinariapolítica". 0 primeiro aspecto considerado por Weber é a adoção, nos Estados Unidos, do regime plebiscitário puro, referindo-se ao presidencialismo. Em princípio, a experiênciapartidária dos EUAparece ser muito semelhante à dos ingleses, também marcada por partidos sem disciplina. Mas, diferentemente do caso inglês, entre os norte-americanos o marco foi 0 ano de 1824, quando da eleição de Andrew 
Jackson à Presidência . A semelhança com a experiência inglesa é que, também nos EUA, a força mais dinâmica veio da política local que se tornou o "ponto de partida da nova evolução". No entanto, o marco decisivo foi $1840 .{ }^{5}$ A partir daí a máquina política iria tomar conta definitivamente do partido. A explicação a essa precocidade feroz da dominação da máquina dada por Weber está na natureza do sistema político adotado no país, o presidencialismo, que fazdo chefe do Executivo um "senhorda distribuição dos empregos" a seus aliados. Além disso, dada a natureza da divisão dos poderes, o sistema presidencialista concentraria grande podere autonomia no Presidente.

Em relação ao poder de nomeação do Presidente, determina-se uma lógica de força ao jogo político. Um spoil system que significa a distribuição de cargos "na administração federal aos partidários do candidato vitorioso". Weber estima que nos EUA o Presidente tem a atribuição de nomear até quatrocentos mil cargos espalhados pelo país, fazendo disso um importante recurso de poder para o partido vitorioso. Muito semelhante ao caso brasileiro, onde o Presidente da República também tem a disposição centenas de milhares de cargos na administração federal para negociar com aliados e usar como uma fundamental moeda de troca no jogo político. Além da rica dinâmica política interna dos partidos norte-americanos e toda a disputa que se trava e travada nesses partidos nas convenções, na nomeação das candidaturas, fenômeno observado até hoje, Weber observa que por força da separação dos poderes, fundamento do sistema político americano, o Presidente pode eventualmente ser eleito sem apoio do parlamento, podendo inclusive antagonizar com o Legislativo. Esse é, pelo menos, o resultado do presidencialismo brasileiro no qual, em vários episódios importantes, os presidentes entram em conflito com o Legislativo, produzindo crises políticas sérias, como se sabe.

Se no sistema inglês de maquinaria política nasce o election agent, nos EUAfaz aparecer a figura política do boss, que é "um empresário político capitalista, que busca votos eleitorais em benefício próprio, correndo os riscos e perigos peculiares a essa atividade". o boss norte-americano aparece na análise de Weber como uma figura política de maior relevância do que a figura política do election agent inglês. Seu espírito éeminentemente capitalista. Antes de ser político, o boss era advogado, comerciante agiota financeiro, ou seja, uma pessoa experiente em ganhar dinheiro e "obter os meios de lançar as primeiras

4 Jackson, do Partido Democrata, obteve nas eleições presidenciais de 1824 uma votação popular superior à votação obtida na Câmara dos Representantes. Na ocasião, foi empossado John Quincy Adams. Nas eleições de 1828 Jackson é eleito com expressiva votação. Em 1832 é reeleito Presidente dos EUA.

5 Em 1840 é eleito Willian Henry Harrison à Presidência, mas Weber não explicita em seu texto porque considera este ano como marco da mudança da política norte-americana. Na ocasião, Harrison morre vítima de pneumonia, em abril de 1841, tornando-se o primeiro Presidente a morrer no cargo. 
bases em lograr controle de certo número de votos". O boss típico, reforça Weber é "antes de tudo um homem dos meios capitalistas que financiam eleições". Seu papel político é reforçado em função de sua capacidade de articulação em obter recursos financeiros para o partido, sobretudo quando consegue a maioria dos fundos que o empresariado destina aos partidos. Além do mais, o boss é o sujeito que consegue driblar as imposições da legislação de controle de gastos de campanha, já existentes nos EUA na época. Sobre isso Weber diz ironicamente que qualquer político que "queira violar impunemente as leis dos Estados deve obter, antecipadamente, a conveniência dos bosses, destinando-lhes certa soma de dinheiro, sob pena de enfrentar as maiores dificuldades".

Outras qualidades da personalidade do boss norte-americano é sua discrição, um homem que "trabalha na obscuridade", geralmente não participa de debates e assembléias públicase sempre "conserva silêncio". É a ausência absoluta de qualquer idealismo e a frieza: "ele só busca o poder, seja como fonte de riqueza, seja pelo próprio poder". E só aceita cargos de importância, como o de senador, em função de sua atribuição na distribuição dos cargos públicos. Sobre o papel desempenhado pelo boss na política partidária moderna, é bastante ilustrativa a análise de Weber para a política brasileira atual em que essas figuras vêm protagonizando várias situações de mal uso de volumosos recursos de campanhas políticoeleitorais e servindo como mediadores de influências e interesses duvidosos no interior dos governos. Agindo sem conhecimento do público mas com grande influência dentro das burocracias e agências públicas, tal como aconteceu durante o governo Collor (1990-92), e mesmo recentemente no governo do Partido dos Trabalhadores.

Um aspecto que Weber chama a atenção quando analisa a evolução dos partidos nos Estados Unidos é o sistema de distribuição de cargos e vantagens em que, em muitos casos, ocorre a nomeação a algum cargo público ao fiel militante partidário seja feita contra 0 pagamento de certa soma de dinheiro, com existência inclusive de uma tabela, com preços diferentes segundo o tipo de cargo a ser ocupado. Parece absurdo especialmente quando se trata de um país como os EUA, mas Weber não pondera: "trata-se de um sistema de venda de posições", semelhante ao quefora praticado nas monarquias medievaise pela Igreja O fenômeno a que Weber está chamando a atenção éo patrimonialismo norte-americano, isto é, o uso do Estado pelo grupo no poder que vende o público em benefício privado.

Esse sistema de exploração de ocupação e venda de cargos, faz dos partidos "empresa política dotada de forte estrutura capitalista" organizada, rígida e hierárquica, "de alto a baixo". Segundo Weber, esse sistema levado às últimas consequências seria desastroso, dada a corrupção generalizada dos funcionários e a ineficiência administrativa. Para um país "novo" ede recursos ilimitadosépossivel, mas mesmo assim, pondera Weber, reformas administrativas 
que objetivem dar mais eficiência e racionalidade ao funcionamento da burocracia estatal, podem fazer com que esse "sistema esteja condenado a morrer lentamente". 0 autor estáse referindo ao Civil Service Reform, programa que atendia a esses objetivos efortalecia a figura do funcionário de carreira em detrimento do funcionário político, ocupado por um diletante e muitas vezes sem o devido preparo técnico para exercer a função. Se as medidas do Civil Service Reform são importantes para a administração pública, certamente também irão produzir mudanças na dinâmica do spoil system e na própria estrutura partidária, mas isso Weber não teve condiçoes de averiguar.

Se as experiências inglesa e norte-americana são exemplos marcantes da evolução dos partidos, no sentido de uma maior burocratização, Weber finalmente vai se ocupar do caso alemão nos trechos finais de $A$ Politica. A primeira observação que 0 autor faz diz respeito à fraqueza do Parlamento e sua dificuldade em formar lideranças e projetar essas lideranças para postos de poder. É claro que Weber se refere ao domínio carismático de Bismarck, que eclipsava as lideranças parlamentares. Além do mais, o Reichstag alemão não dispunha de instrumentos de controle da administração pública, tornando ainda mais difícil a formação de lideranças no exercício da atividade parlamentar. Por outro lado, aquilo que os parlamentares americanos faziam com fácil desenvoltura, a nomeação de cargos, na Alemanha, nem isso o deputado poderia fazer, em função da forte tradição alemã da instituição do funcionário de carreira. 0 que Weber demonstra é que em seu país, a ocupação de postos administrativos importantes por funcionários especializados já vem de muito tempo. A consequência desse domínio dos funcionários é que no limite, até mesmo os postos de caráter político podem ser ocupados por esses funcionários.

No sistema político da Alemanha Imperial, com uma liderança forte, parlamento impotente e lideranças eclipsadas diante de um poder burocrático, Weber parece se inclinar a aceitar o parlamentarismo como alternativa. Porém, observa criticamente que nenhuma das principiais forças políticas do país estava disposta a encarar a tarefa de mudança do seu sistema político. Tanto o Partido do Centro (Centrum) como a Social-Democracia pareciam estar satisfeitos com sua condição de minoria, por não enxergarem no parlamentarismo uma solução qualitativamente diferente.

Quais as lições da experiência da Inglaterra e dos Estados Unidos para a Alemanha e mais ainda para o exercício da vocação política? No caso do país de Weber, as condições reais em que se forjava a atividade política, tornavam mais críticos os processos nas quais as lideranças são forjadas. Weber assevera que grandes lideranç̧as políticas, como Lincoln nos EUA e Gladstone na Inglaterra, foram possíveis porque estavam apoiadas numa estrutura partidária do tipo plebiscitária, com uma organização rígida e militância 
disciplinada. Weber formula a questão com uma escolha a ser feita: ou se quer uma liderança política autenticamente vocacionada com fortes traços carismáticos ou se quer um político profissional sem qualidades de chefe. Os custos da primeira opção seriam aceitar a existência da máquina nos partidos e, conseqüentemente, uma maior burocratização, já os custos da segunda opção seriam uma política sem líderes autênticos.

Recebido em novembro de 2004. 